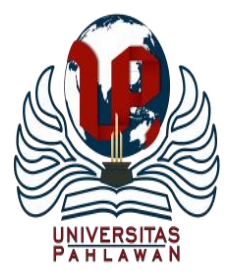

Edukatif : Jurnal Ilmu Pendidikan Volume 3 Nomor 2 Tahun 2021 Halm 562 - 568 EDUKATIF: JURNAL ILMU PENDIDIKAN

Research \& Learning in Education

https://edukatif.org/index.php/edukatif/index

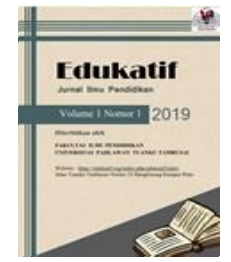

\title{
Pemikiran Kartini Mengenai Pendidikan Perempuan
}

\author{
Tia Amanda Pratiwi MD ${ }^{1 凶}$, Hudaidah $^{2}$ \\ Universitas Sriwijaya, Indonesia ${ }^{1,2}$ \\ E-mail : ttia6298@ gmail.com ${ }^{1}, \underline{\text { hudaidah@fkip.unsri.ac.id }}^{2}$
}

\begin{abstract}
Abstrak
Pendidikan perempuan adalah suatu sistem penyampaian ilmu yang diberikan kepada para perempuan, dimana pendidikan untuk perempuan maupun laki-laki sudah seharusnya setara. Penelitian ini memiliki tujuan untuk mengetahui bagaimana pemikiran serta perjuangan RA.Kartini dalam bidang pendidikan terutama pendidikan perempuan. Metode penelitian ini yaitu menggunakan metode kualitatif dan jenis kajian yang digunakan adalah kajian pustaka. Dimana penelitian ini dilakukan lewat berbagai macam sumber informasi kepustakaan seperti buku, jurnal ilmiah, ensiklopedia, majalah, koran, dokumen dan lainnya. Raden Ajeng Kartini merupakan tokoh atau pejuang perempuan yang memiliki peran penting dalam pendidikan terutama pendidikan terutama pendidikan perempuan di Indonesia. Ia lahir di Jepara, Jawa Tengah pada 21 April 1879 atau 28 Rabi'ul Akhir tahun Jawa 1808. Ia merupakan anak dari sepasang suami istri bernama Raden Mas Adipati Ario Sosroningrat dan M.A. Ngasirah. Pada masa itu, pendidikan bagi perempuan merupakan perihal yang sulit untuk didapatkan karena banyaknya peraturan dan larangan yang ada pada masa itu, sehingga membuat kartini memiliki pemikiran yang membuat ia memperjuangkan pendidikan bagi kaum wanita di Indonesia. Kartini juga mampu memperjuangan hak perempuan dalam mendapatkan pendidikan yang sama dengan pendidikan yang ditempuh oleh perempuan pada masa itu.
\end{abstract}

Kata Kunci: Pemikiran, Kartini, Pendidikan, Perempuan.

\begin{abstract}
Women's education is a system of delivering knowledge that is given to women, where education for men or women should be equal. This study aims to see how RA Kartini's initiative and struggles in the field of education, especially women's education. This research uses qualitative methods and the type of study used is literature review. This research was carried out through various sources of literature information such as books, scientific journals, encyclopedias, magazines, newspapers, documents, and others. Raden Ajeng Kartini is a female figure or fighter who has an important role in education, especially education for women in Indonesia. She was born in Jepara, Central Java on 21 April 1879 or 28 Rabi'ul Akhir of Java 1808. She is the daughter of a spouse named Raden Mas Adipati Ario Sosroningrat and M.A. Ngasirah. At that time, education for women was a subject that was difficult to obtain because of many regulations and prohibitions that existed at that time, so that Kartini had thoughts that made her fight for education for women in Indonesia. Kartini was also able to fight for women's rights to get the same education as the education achieved by women at that time.
\end{abstract}

Keywords: Thought, Kartini, Education, Women.

Copyright (c) 2021 Tia Amanda Pratiwi, Hudaidah

$\triangle$ Corresponding author

Email : ttia6298@gmail.com

DOI : https://doi.org/10.31004/edukatif.v3i2.386

ISSN 2656-8063 (Media Cetak)

ISSN 2656-8071 (Media Online)

Edukatif : Jurnal Ilmu Pendidikan Vol 3 No 2 Tahun 2021 p-ISSN 2656-8063 e-ISSN 2656-8071 


\section{PENDAHULUAN}

Pendidikan merupakan perihal yang sering dibicarakan dan diperdebatkan. Pendidikan sangat penting bagi semua kalangan karena pendidikan berfungsi sebagai usaha untuk mengembangkan dan membina kepribadian manusia dalam aspek rohani dan jasmani, yang dilakukan secara bertahap. Ahli filsafat pendidikan banyak yang memberikan arti pendidikan yaitu suatu proses bukan suatu seni ataupun teknik. (Arifin, 2010).

Ada banyak tokoh yang menjadi pejuang pendidikan, seperti Ki Hajar Dewantara, KH. Hasyim Asy'ari, KH. Ahmad Dahlan, Dewi Sartika, dan juga Raden Ajeng Kartini. Masing-masing dari beliau memiliki perannya sendiri dan sangat penting dalam pendidikan di Indonesia. Selain dari mereka juga masih banyak orang yang memiliki peranan penting dalam pendidikan di Indonesia.

Kartini salah satunya, ia merupakan seorang bangsawan dan cucu perempuan dari Pangeran Ario Tjondronegoro yang merupakan seorang Bupati Demak. Pada saat itu, Kartini akan menikah. Sebelum hari pernikahan, Kartini harus mengalami yang namanya pengitan. Dalam masa pingitan itulah Kartini memiliki cita-cita dan pemikiran untuk berjuang demi kebebasan pembelajaran perempuan. Cita-cita dan pemikiran itu muncul karena selama masa pingitan, Kartini menghabiskan waktunya dengan membaca bermacam buku dan majalah yang mayoritas buku itu diterbitkan oleh Belanda. Dari aktivitas membaca itulah Kartini mendapatkan pemahaman mengenai perempuan juga berhak memiliki kebebasan hidup sebab perempuan di dataran Eropa jauh lebih maju dari Indonesia. (Kholisoh, 2016).

Pengetahuan dan juga keinginan Kartini mengenai emansipasi perempuan semakin kuat. Meskipun tidak mengenyam pendidikan yang tinggi, tetapi Kartini bertekad untuk terus belajar mencari wawasan sebanyak mungkin melalui membaca maupun menulis. Menurut Kartini, perempuan haruslah memiliki pendidikan yang tinggi, karena wanita lah yang menjadi tempat pembelajaran awal bagi anak-anaknya kelak. Sehingga perempuan harus cerdas agar bisa membantu mencerdaskan anaknya dirumah. (Kholisoh, 2016).

Pendidikan yang dilakukan dan diinginkan oleh Kartini adalah pendidikan untuk perempuan. Pendidikan untuk perempuan ini adalah suatu sistem penyampaian ilmu yang diberikan kepada para perempuan, dimana pendidikan untuk perempuan maupun laki-laki sudah seharusnya setara. Tidak ada perbedaan dalam hak untuk belajar, semuanya sama baik yang miskin maupun kaya, pria maupun wanita. Belajar merupakan suatu hal yang wajib dan diharuskan oleh Islam bagi setiap muslim dan muslimah. Akan tetapi, pendidikan perempuan dan pendidikan laki-laki sangatlah jauh berbeda dalam dunia nyata. Padahal di dalam agama islam, pendidikan semua orang baik itu pria maupun wanita tidak berbeda.

Islam memandang perempuan sebagai ciptaan Allah SWT. yang istimewa. Islam tidak pernah melarang bahkan memberikan kebebasan dan kemerdekaan kepada perempuan termasuk mengenai pendidikan yang akan ditempuh oleh perempuan itu sendiri. Islam tidak pernah memandang beda antara pria dan wanita. Di dalam islam, semua orang baik pria maupun wanita berhak memutuskan sampai mana pendidikan yang akan mereka tempuh (Muthoifin et al., 2017).

Adanya suatu anggapan bahwa perempuan hanya mengurus keperluan rumah tangga dan perempuan merupakan makhluk yang lemah bukan berarti perempuan tidak berhak mendapatkan pendidikan. Hal ini lah yang membuat Kartini ingin memperjuangkan pendidikan perempuan dan mempelopori pendidikan perempuan pertama di Indonesia.

Karena Kartini dan para pejuang lainnya lah kita sebagai generasi muda dapat mengenyam pendidikan setinggi-tingginya. Tokoh-tokoh yang memiliki peranan penting bagi perempuan yaitu Dewi Sartika, Cut Nyak Dhien, Hajjah Rangkayo Rasuna Said, Maria Walanda Maramis, dan masih banyak lagi. Cut Nyak Dien, Raden Dewi Sartika, Rohana Kudus, Rahmah El-Yunusiyah, serta Raden Ajeng (R.A.) Kartini merupakan orang-orang yang mengganti cara berpikir masyarakat tentang perempuan, dan membuat perubahan mengenai 
kedudukan perempuan menjadi sejajar dengan laki-laki, terlebih dalam perihal pendidikan (Muthoifin et al., 2017).

Berdasarkan uraian diatas, penelitian ini memiliki tujuan untuk mengetahui bagaimana pemikiran serta perjuangan RA.Kartini dalam bidang pendidikan terutama pendidikan perempuan. Dimana pendidikan perempuan ini dianggap memiliki peran penting dalam mengangkat derajat dan martabat suatu bangsa dan negara.

\section{METODE PENELITIAN}

Penelitian mengenai Pemikiran Pendidikan RA.Kartini ini lebih banyak menggunakan metode penelitian kualitatif. Dan penelitian ini bersifat deduktif dan induktif. Cara menjelaskan penelitian mengenai Pemikiran pendidikan oleh RA.Kartini dengan cara deskriptif yaitu menjelaskan beberapa peristiwa apa saja yang terjadi di dalam kehidupan RA.Kartini. (Moleong, 2018). Pendekatan historis dan biografi juga digunakan untuk penelitian mengenai Pemikiran Pendidikan RA.Kartini ini yaitu pendekatan dengan menceritakan suatu peristiwa sejarah yang dialami seseorang di dalam hidupnya secara sistematis (Creswell, 2014) dimana dasar penelitian ini terdapat pada penelaahan sumber sejarah, perekaman data, pengevaluasian sumber sejarah, serta interpretasi sumber sejarah. (Arikunto, 2009) Penelitian ini juga menggunakan jenis penelitian studi pustaka, dimana penelitian mengenai Pemikiran Pendidikan RA.Kartini ini dilakukan lewat berbagai macam sumber informasi kepustakaan seperti buku, jurnal ilmiah, ensiklopedia, majalah, koran, dokumen dan lainnya. Penulis menggunakan studi pustaka karena lebih efektif dan efisien dalam menganalisis tentang pemikiran pendidikan Kartini. (Sukri et al., 2016).

\section{HASIL DAN PEMBAHASAN PENELITIAN}

Raden Ajeng Kartini lahir di Jepara, Jawa Tengah pada 21 April 1879 atau 28 Rabi’ul Akhir tahun Jawa 1808. Ia lahir dari sepasang suami istri bernama Raden Mas Adipati Ario Sosroningrat dan M.A. Ngasirah. Pada saat Kartini lahir, ia sudah memiliki "darah biru" dan juga "darah pesantren". Ayah Kartini, atau yang sering dipanggil Sosroningrat merupakan seorang bupati yang berpendidikan tinggi. Beliau merupakan orang yang pandai menulis dan pandai dalam bahasa Belanda. Dan ibunya, Ngasirah merupakan seorang anak dari Nyai Hajja Siti Aminah dan Kyai Haji Madirono, dimana beliau merupakan seorang pengajar agama di Teluwakur, Jepara. (Rosyadi, 2016) . Karena itu, Kartini memiliki hak untuk menggunakan gelar Raden Ajeng yang merupakan gelar kebangsawaan. (Abdul, 2020).

Pada masa Kolonial Belanda, terdapat suatu peraturan yang dibuat oleh pemerintah Kolonial Belanda dimana seseorang Bupati wajib menikah dengan sesama generasi bangsawan. Sehingga dia yaitu Sosroningrat menikah lagi dengan Raden Ayu Muryam yaitu generasi dari raja Madura. (Rosyadi, 2016).

R.A Kartini merupakan anak kelima dari kesebelas saudaranya, baik kandung maupun tiri. Kartini merupakan anak perempuan paling tua diantara saudara-saudara kandungnya. Kakak R.A Kartini, Sosrokartono merupakan orang yang pandai dalam bidang bahasa. Kartini bersekolah sampai usia 12 tahun di ELS (Europese Lagere School) yang merupakan sekolah yang didirikan untuk orang-orang Belanda dan Bangsawan. (Hartutik, 2015) Pada saat Kartini bersekolah, Kartini mengalami diskriminasi oleh gurugurunya. Kartini menceritakan hal itu kepada Stella Zeehandellar yang merupakan salah satu sahabatnya, ia menulis: "Para orang Belanda itu menertawakan serta mengejek kebodohan kami, hendak namun kami berupaya maju, setelah itu mereka mengambil perilaku menentang kami. Aduhai! Betapa banyaknya dukacita dulu pada masa kanak-kanan di sekolah; para guru serta banyak di antara teman-teman mengambil perilaku permusuhan kepada kami”. (Rosyadi, 2016). 
Pada saat berusia 12 tahun, Kartini mengalami masa pingitan. Masa pingitan itu merupakan salah satu tradisi di kalangan tertentu dimana seorang gadis remaja tidak diperbolehkan untuk keluar rumah dalam waktu yang telah ditentukan. (Rosyadi, 2016). Selama masa pingitan, Kartini menghabiskan waktunya dengan membaca majalah-majalah dan buku-buku Bahasa Belanda, Kartini juga berkomunikasi melalui surat dengan teman-temannya dari Eropa. (Pane, 2008) Setelah mengalami masa pingitan selama kurang lebih 4 tahun, Kartini memperoleh kebebasannya kembali, yaitu kebebasan yang tidak didapatkan setelah ia meninggalkan bangku sekolah. (Toer, 2012) Sejak saat itulah, Kartini melakukan beberapa perubahan dalam kebiasaan pergaulan dengan adik-adiknya. Mereka tidak kaku lagi dalam bergaul dan adik-adiknya tidak perlu berjongkok untuk menyembah dan sebagainya.

Bertepatan pada 8 November 1903 Kartini menikah dengan Bupati Rembang Raden Adipati Djojo Adiningrat serta setelah itu mengikuti suaminya ke Rembang. (Rosyadi, 2016) . Kartini menerima pinangan dan menikah sebab suaminya yaitu R.M. Joyohadiningrat pernah menempuh pendidikan di Belanda serta sangat menunjang cita-cita Kartini untuk mendirikan sekolah perempuan. (Kholisoh, 2016). Pada 13 September 1904, Kartini melahirkan seorang bayi laki-laki yang diberi nama Susalit. Tetapi, 4 hari sehabis melahirkan Susalit, tepatnya pada tanggal 17 september, Kartini menghembuskan napas terakhirnya pada umur 25 tahun.

Pemikiran Raden Ajeng Kartini mengenai pendidikan perempuan terdapat pada buku yang ia tulis. Buku yang Kartini tulis berjudul Habis Gelap Terbitlah Terang (Door Duisternis Tot Lieht). Di dalam buku ini, Kartini menuliskan tentang keinginannya untuk memperjuangkan kaum wanita pada saat itu agar mendapatkan pendidikan yang layak. (Widiarto, 2016).

Kartini memiliki kecerdasan yang luar biasa dan itu digunakannya untuk memajukan kecerdasan bangsa terutama perempuan. Raden Ajeng Kartini memiliki dan mewariskan sikap progresif dari Kakeknya yaitu Pangeran Ario Tjondronegoro IV dari Demak da juga ayahnya R.M.A.A. Sosroningrat. Beliau selalu mengingatkan kepada anak dan cucunya bahwa pengetahuan sangat penting untuk kemajuan bangsa dan negara, dan ilmu pengetahuan sebagai kebahagian bagi diri sendiri dan masyarakat, tanpa pendidikan kita akan mengalami kemunduran dan tidak memiliki kebahagiaan. (Pramudawardhani \& Estiana, 2019).

Bagi Kartini pendidikan sudah menjadi hal yang penting dan mengakar kuat dalam keluarganya. Kartini memiliki beberapa sahabat yang merupakan orang berkebangsaan Belanda, salah satunya bernama Nyonya Abendanon. Kartini sering mengirimkan surat dan bertukar cerita dengan sahabat-sahabatnya yang merupakan orang-orang Belanda . Di dalam surat yang ditulis oleh Kartini, ia menceritakan berbagai macam hal seperti kegelisahannya mengenai situasi sosial, adat, dan kultur yang mengekang bumi putra untuk mendapatkan pendidikan yang layak. (Widiarto, 2016) .Selain itu, Kartini juga pernah menceritakan mengenai Kakeknya, Tjondronegoro IV, yang sangat dia kagumi dan banggakan. Beliau merupakan seorang laki-laki yang sangat menaruh perhatian terhadap pendidikan dunia, dia juga memberikan pendidikan barat yang baik kepada putra, putri dan cucu-cucunya. (Pramudawardhani \& Estiana, 2019).

Kartini banyak menceritakan berbagai kejadian dan juga pemikirannya terhadap perempuan melalui surat-surat yang ia kirim kepada sahabat-sahabatnya. Sebagian besar dari surat-suratnya berisi tentang pendapatnya mengenai perempuan yang mempunyai peran besar dalam memajukan peradaban dunia dan ketertarikannya dengan gerakan-gerakan emansipasi di Eropa. Di dalam suratnya, Kartini juga menceritakan keprihatinannya mengenai buta huruf yang dialami oleh perempuan karena tidak tersedianya pendidikan yang tinggi dan pantas bagi perempuan.

Kartini berpendapat bahwa pendidikan perempuan merupakan pendidikan yang sudah seharusnya diterima oleh perempuan tidak peduli kaya, miskin, status social, ras, dan juga yang lain. Bukan hanya lakilaki saja yang dapat menempuh pendidikan setinggi mungkin, perempuan juga berhak dan bisa menempuh 
pendidikan yang mereka inginkan. Tidak ada batasan untuk mendapatkan suatu pendidikan, karena semua orang berhak untuk mendapatkan pendidikan yang mereka mau. (Megawati, 2018).

Konsep pendidikan untuk perempuan yang diajukan oleh Kartini didasarkan pada kisah perjalanan hidup dan pandangannya terhadap lingkungan dan kehidupan yang ia alami. Kartini merupakan salah seorang perempuan yang memiliki kecerdasan dan pendidikan yang layak, sehingga ia memiliki suatu pemikiran bahwa hal yang sangat penting bagi semua orang adalah pendidikan karena pendidikan berperan penting dalam memajukan bangsa dan negaranya. Kartini yang mengalami banyak hal dalam menjalani pendidikannya membuat ia memiliki tekad yang kuat untuk mengubah pandangan semua orang akan pentingnya pendidikan.

Salah satu faktor yang menyebabkan Kartini memiliki pemikiran mengenai pendidikan perempuan yaitu ia pernah mengalami diskriminasi karena adanya aturan bahwa pribumu tidak boleh mendapatkan nilai bagus dan lebih dari anak-anak berkulit putih, perempuan harus berhenti mengenyam pendidikan karena adat dan budaya yang ada. Kartini memiliki sahabat-sahabat dan saling mengirim surat. Oleh sebab itulah Kartini memiliki pandangan luas dan terbuka dalam memperjuangkan hak-hak pendidikan bagi perempuan. (Megawati, 2018).

Bagi Kartini pendidikan perempuan sangat penting, sehingga Kartini memiliki beberapa konsep untuk pendidikan perempuan yaitu sebagai berikut.

Pertama, Di dalam keluarga, Perempuan merupakan tempat pendidikan pertama bagi anak-anaknya. Perempuan berperan sebagai Ibu di keluarga, perempuanlah yang memberikan pendidikan pertama bagi anakanaknya kelak. Kartini menyampaikan hal ini ke dalam surat-surat yang ia tulis dan kirimkan kepada sahabatsahabat penanya. Kartini juga menyampaikan bahwa tangan seorang ibu merupakan penentu masa depan. (Pane, 2008) Seorang ibu memiliki peran penting dalam pendidikan non-formal yang akan ditempuh anakanak mereka. Perempuan berperan penting dalam pendidikan pertama bagi anak-anak sebelum sekolah sehingga perempuan memerlukan pendidikan yang layak untuk mendidik dan membimbing anak-anaknya kelak.

Kedua, Perempuan menjadi pembawa peradaban. Perempuan tidak hanya memiliki peran penting di dalam rumah atau keluarga. Akan tetapi perempuan juga memiliki peran penting dalam peradaban dunia, karena apabila perempuan disuatu negara tersebut tertinggal maka tidak akan maju negara tersebut. Hal itu disampaikan Kartini kepada Mr. Abendanon di dalam suratnya bahwa ia ingin mendirikan sekolah untuk perempuan-perempua di negerinya. (Pane, 2008).

Ketiga, Pendidikan memiliki peran penting dalam mendidik jiwa dan budi seseorang, karena tidak ada guna apabila seseorang yang cerdas pikirannya tetapi tidak dengan perilakunya. Kartini juga menyampaikan dalam suratnya bahwa pendidikan tidak hanya mempertajam pikiran tetapi budinya atau perilakunya juga harus dipertinggi. Kartini juga mengatakan bahwa pendidikan budi tidak hanya didapatkan dari pendidikan sekolah saja tetapi juga di dalam keluarga itu lah pendidikan budi diperkenalkan dan paling mudah diterapkan dan diajarkan. Perempuan atau ibulah yang memiliki peran penting dalam mengajarkan pendidikan budi tersebut.

Keempat, Kartini berpendapat bahwa bersatunya perempuan dan laki-laki dalam hal memajukan pendidikan akan memberikan manfaat dan perubahan besar dalam kemajuan pendidikan di suatu bangsa. Pendidikan perempuan dengan laki-laki sudah seharusnya disama ratakan karena perempuan memiliki peran yang sama pentingnya dengan laki-laki, sehingga perempuan dan laki-laki dapat bekerja sama dalam memajukan pendidikan.

Terakhir, pendidikan bagi cinta tanah air diberikan kepada generasi muda untuk memajukan dan membangun kesejahteraan suatu bangsa dan negara. Kita sebagai perempuan boleh memiliki pendidikan dan 
pemikiran yang luas. Akan tetapi, tidak boleh melupakan tanah air kita sendiri dan tetap cinta terhadap tanah air kita.

\section{KESIMPULAN}

Pemikiran Raden Ajeng Kartini mengenai pendidikan perempuan terdapat pada buku yang ia tulis. Buku yang Kartini tulis berjudul Habis Gelap Terbitlah Terang (Door Duisternis Tot Lieht). Di dalam buku ini, Kartini menuliskan tentang keinginannya untuk memperjuangkan kaum wanita pada saat itu agar mendapatkan pendidikan yang layak. Kartini adalah salah satu dari banyaknya perempuan yang berjuang untuk pendidikan kaum wanita di Indonesia. Memiliki keluarga dengan pendidikan yang tinggi membuat Kartini memiliki pemikiran dan cita-cita yang tinggi dan luar biasa. Banyak peristiwa yang terjadi pada kehidupan Kartini yang menyebabkan Kartini memiliki pemikiran untuk memajukan pendidikan terutama pendidikan bagi kaum wanita di Indonesia. Pemikiran Kartini mengenai pendidikan perempuan ini muncul karena lingkungan, pengalaman diskriminasi dan seringnya berkomunikasi melalui surat dengan sahabat-sahabatnya yang merupakan orang-orang dari negeri Belanda tersebut. Adapun konsep-konsep pendidikan bagi wanita menurut Kartini yaitu perempuan adalah tempat pertama pendidikan bagi seorang anak, perempuan menjadi salah seorang yang penting dalam memajukan peradaban dunia, perempuan memiliki peran penting dalam pendidikan jiwa dan budi, konsep pendidikan perempuan yang sudah seharusnya setara dengan laki-laki agar dapat bekerja sama untuk memajukan pendidikan, dan juga konsep mengenai pendidikan cinta tanah air. Dari pemikiran Kartini ini, kita dapat mengetahui bahwa kesamaan dalam hak dan kewajiban bagi perempuan adalah hal yang penting karena pria dan wanita dapat bersatu untuk memajuan bangsa dan negaranya. Kartini juga mampu memperjuangan hak perempuan dalam mendapatkan pendidikan yang sama dengan pendidikan yang ditempuh oleh perempuan pada masa itu

\section{DAFTAR PUSTAKA}

Abdul, M. R. (2020). Ibu Sebagai Madrasah Bagi Anaknya: Pemikiran Pendidikan R.A. Kartini. Journal of Islamic Education Policy, 5(2), 91-98. https://doi.org/10.30984/jiep.v5i2.1350

Arifin, M. (2010). Filsafat Pendidikan Islam (edisi 1). Jakarta :Bumi Aksara.

Arikunto, S. (2009). Manajemen penelitian. Rineka Cipta.

Creswell, J. w. (2014). Penelitian kualitatif \& desain riset: memilih diantara lima pendekatan. Penelitian kualitatif \& desain riset : memilih diantara lima pendekatan.

Hartutik. (2015). R.A. Kartini : Emansipator Indonesia Awal Abad 20. Jurnal Seuneubok Lada, 2(1), 86-96. https://ejurnalunsam.id/index.php/jsnbl/article/download/559/413/

Kholisoh, S. (2016). Konsep Pendidikan Perempuan R.A. Kartini dalam Buku Habis Gelap Terbitlah Terang. E-Repository Perpus IAIN Salatiga, 100. http://e-repository.perpus.iainsalatiga.ac.id/1427/1/skripsi jadi.pdf

Megawati, M. (2018). Konsep pendidikan perempuan perspektif $R A$ Kartini dan relevansinya dengan Pendidikan Islam. http://digilib.uinsby.ac.id/24708/

Moleong, L. J. (2018). Metodologi penelitian kualitatif (Edisi revi). PT Remaja Rosdakarya.

Muthoifin, M., Ali, M., \& Wachidah, N. (2017). Pemikiran Raden Ajeng Kartini Tentang Pendidikan Perempuan Dan Relevansinya Terhadap Pendidikan Islam. Profetika: Jurnal Studi Islam, 18(1), 36-47. https://doi.org/10.23917/profetika.v18i1.7690

Pane, A. (2008). Habis Gelap Terbitlah Terang. Balai Pustaka.

Pramudawardhani, I., \& Estiana, E. (2019). PERJUANGAN DAN PEMIKIRAN R.A. KARTINI TENTANG PENDIDIKAN PEREMPUAN. KERATON : Journal of History Education and Culture, Vol. 1, No, 41- 
568 Pemikiran Kartini Mengenai Pendidikan Perempuan - Tia Amanda Pratiwi, Hudaidah DOI: https://doi.org/10.31004/edukatif.v3i2.386

55.

Rosyadi, I. (2016). R.A KARTINI : Biografi Singkat 1879-1904 (A. Safa (ed.)). Garasi.

Sukri, S., Handayani, T., \& Tinus, A. (2016). Analisis Konsep Pemikiran Ki Hajar Dewantara Dalam Perspektif Pendidikan Karakter. Jurnal Civic Hukum, 1(1), 33. https://doi.org/10.22219/jch.v1i1.10460

Toer, P. A. (2012). Panggil Aku Kartini Saja. Lentera Dipantara.

Widiarto. (2016). Pemikiran Pendidikan Kartini. Republika.Co.Id. https://republika.co.id/berita/o5va0621/pemikiran-pendidikan-kartini 